\title{
Reimagining Parenting Possibilities: Towards Intimate Justice
}

\author{
ESTHER IGNAGNI \\ Ryerson University, Canada \\ ANN FUDGE SCHORMANS \\ McMaster University, Canada
}

\begin{abstract}
At the heart of this paper is a collaboratively created script representing a line of analysis from the Reimagining Parenting Possibilities Project. The script is performed as a forum theatre scene used to disseminate findings from this ongoing research project. Forum theatre, an exemplar of Augusto Boal's "theatre of the oppressed," invites audience members into a scene, inventing through embodied performance and improvisation analyses and interventions in shared social dilemmas (Boal, 2006). The project rests upon our joint investments in exploring how the denial and containment of parenthood for people labeled with intellectual and developmental disabilities stems from enduring ableist views as to who is deemed "fit" to raise future citizens, and related efforts to erase disability. We introduce this work with a prologue - offering context for the ableist dynamic and intimate injustices that unfold in the scene. We also provide some background on how we developed the scene, attending to the democratizing and transformative potential of our methodology. Finally, by way of an epilogue, we sketch a number of questions about the scene's potential to promote intimate and disability justice.
\end{abstract}

KEYWORDS disability; parenthood; forum theatre; co-production; ableism

\section{Prologue}

There has been long, contested, and complicated legal debate over human rights to procreation and parenthood for disabled persons, relative to topics such as abortion, involuntary sterilization, marriage, and residency (Saxton, 2013; Turner, 2006); of fundamental concern is the accessibility of parenthood possibilities. For disabled people, "right to parenthood" has been framed as a human right, and was formally enshrined in Article 23 of the UN Convention on the Rights of Persons with Disabilities (CRPD) (UN, 2006). 
Consonant with the general thrust of the CRPD, and responding to a violent history of the denial of parenthood rights (or perhaps more expansively, rights to building family), the Article seeks to protect negative freedoms by limiting state restrictions of disabled people's freedom to marry, to enter relationships, to cohabitate, and to exercise reproductive choice and control (Anderson \& Phillips, 2012; Shakespeare, 2014). The CRPD also sets out positive rights by requiring "active measures aimed at supporting and enabling (disabled) persons and their communities" to access the opportunity for intimate life, including parenthood (Anderson \& Phillips, 2012, p. 1-2).

For disabled people, possible aspirations towards parenthood have been systematically foreclosed - as evidenced by a eugenic history of state regulation of and intrusion into almost every area of their intimate lives, including their friendships, sexual expression, marriage, and reproductive choice and control (Kevles, 1985; Malacrida, 2015; McLaren, 2015). In Canada, segregated institutionalization, restrictive marriage laws, and forced sterilization were all part of a social policy response to the inaccurately assumed threat of inherited mental, physical, and moral deficiency (Dowbiggin, 1995; Malacrida, 2015). Although traditional eugenic legislation has since been rescinded, its legacy continues to reverberate among disabled people in Canada and elsewhere through informal means and through newgenic legislation. Indeed, as some have argued, eugenics may have simply changed form, finding new expressions - newgenics - as it continues to interrupt and disqualify disabled people's efforts and aspirations to create families of their choosing (Duster, 2003; Malacrida, 2015). ${ }^{1}$ One way this reverberation is felt is through the continued denial of disabled people's positive rights and resources to pursue parenthood; increasingly inadequate support for families is seen, for example, in the insufficient of social housing, restricted childcare subsidies to parents who are not in paid employment, social assistance rates that maintain families in poverty, the loss of disability assistance for disabled parents upon marriage, the limited availability of accessible child and family-centric spaces (play centres, parent-child drop ins, daycares), limited accessible information on family and reproductive health, and so forth. While family forms and parenthood arrangements are undergoing profound social transformation (National Council on Disability, 2012), disabled people continue to be uncelebrated as parents, viewed as unacceptably transgressive, even when they attempt to approximate the most historically conventional family forms, let alone when they agentively elect to remain "child-free."

Underpinning the denial of disabled people's intimate rights to parenthood are the ableist assumptions about who counts as a good citizen. Parenthood is

\footnotetext{
1 "Newgenics is a term that recognizes a broad range of medical, political and social practices related to 'improving' human kind on the one hand, and erasing disability and difference on the other. Newgenics moves beyond biological and medical interventions, to encompass systematic gaps and barriers to education, services, policy and supports for disabled people in terms of their sexuality and reproduction" (Eugenics to Newgenics, n.d., n.p.).
} 
normatively a marker of adult citizenship (Plummer, 2003; Turner, 2006). While this does not mean that only those who parent are viewed as "adult citizens," the many barriers to parenthood experienced by disabled people can be felt as a manifestation and a perverse justification of their continued infantilization. Further, according to feminist disability scholar Alison Kafer, disability is culturally threatening because it cannot easily align with the curative imaginary: "an understanding of disability that not only expects and demands intervention, but cannot imagine anything beyond this intervention" (2013, p. 27). Disabled lives at "the convergence of class, moralized gender and race locations" have been imagined as unlivable and granted no claim to shaping the future (Kafer, 2013, p. 27). This is particularly pronounced for people labeled with intellectual and developmental disabilities (from here forward referred to as "labeled people"). Since the figure of the child buttresses normative futures for the state and the human, disabled people are specifically barred from reproductive futurity. To do otherwise, would be to risk exposing the future child and thus all of our futures to disabled parents' pathological nature and nurture (Kilkey \& Clarke, 2010).

At this point a definition of dis/ableism may be helpful. Ableism and disableism (dis/ableism) are not always familiar terms. Analogous to racism, sexism, or heterosexism, dis/ableism refers to "pervasive systems of discrimination and exclusion" (Campbell, 2001, p. 43), but impacts people with cognitive, emotional, sensory, and physical impairments or differences. Dis/ableism emanates from a "culturally embedded network of beliefs, processes and practices about the perfect, typical, fully human, bodily standards" (Campbell, 2001, p. 43). These are reflected in normative ideas about what constitutes health, productivity, beauty, intelligence, and competence, against which disabled, Mad, Deaf, and labeled people are understood to be "diminished humans" (Campbell, 2001, p.43). By dehumanizing and devaluing disabled people, these beliefs fuel the restriction and containment of disabled people's activity and the "socially embedded and engendered ways" in which we undermine their physical and emotional wellbeing (Thomas, 2007, p. 73; Goodley, 2014). To summarize, disabled people's imputed failure to meet cognitive, social, and physical ideals means they are actively disqualified from parenting (through sterilization, lack of sexual health education, denial of opportunities for intimacy, child apprehension, etc.). Eugenic ideals of a good birth, proper home, ideal family, and proper parenting continue to surface in contemporary assessments of who is or isn't fit to be a citizen and to produce future citizens.

\section{Background of the Project}

Reimagining Parenting Possibilities (RPP) grew out of the work of the community organization Strength-Based Parenting Initiative (SPIN). SPIN is 
a user-led provincial network (Ontario, Canada), created and operated by and for parents and prospective parents with disabilities. SPIN provides education and advocacy around experiences and concerns related to parenting and disability. Committed to inclusion, equity, affordability, and justice around parenting resources, SPIN operates from anti-oppression and anti-ableism philosophies as it strives to re-imagine parenting and family life for all disabled, Mad, Deaf, and labeled people.

In its work, the group has repeatedly confronted how people labeled with intellectual and developmental disabilities are acutely marginalized with respect to parenting and parenthood. It was these observations that led to the establishment of $R P P$, an Ontario-wide, community-based, participatory research initiative. Using a co-researcher model, the project attempts to privilege the voices of labeled people. We begin with the experience of disability to re-imagine what we think of as parenting, family, intimacy, and reproductive justice in non-normative and inclusive ways.

We acknowledge the ways in which "intellectual and developmental disability" and "parenting/parenthood" are culturally constructed and socially, economically, and politically mediated. Thus, in this project we (as a research team) are trying to move beyond a phenomenological account towards a critical interpretation. Our project is not framed as therapeutic, but as a means of taking part in the ongoing debates about intellectual and developmental disability and parenting/parenthood in the cultural realm.

\section{The Co-Researcher Teams}

One of our first tasks in the project was to establish a core group of six selfadvocate co-researchers - $R P P$ co-researchers - who have been working alongside academic and community team members on all aspects of the project (for instance, in developing interview guides, training other coresearchers, conducting interviews and data analysis, and disseminating findings). ${ }^{2}$ In addition to the core group, groups of three or four self-advocate co-researchers in five other communities across Ontario were put into place to implement the project in their region. Working with local facilitators, they interviewed service providers and policy makers in order to develop a sense of the resource context in their region. Significantly, they also interviewed labeled people about their parenting experiences, aspirations, and disappointments.

\footnotetext{
${ }^{2}$ Self-advocate refers to a labeled person who advocates for social and political change to improve the life conditions for disabled people and themself.
} 


\section{Our Methodology}

At the direction of the co-researchers we decided to use forum theatre both as a form of analysis and as a means of knowledge and story sharing.

Forum theatre is based on Augusto Boal's (1995, 2002) "theatre of the oppressed" framework for popular education and social change. Boal describes this framework as follows:

a system of physical exercises, aesthetic games, image techniques and special improvisations whose goal is to safeguard, develop and reshape this human vocation, by turning the practice of theatre into an effective tool for the comprehension of social and personal problems and the search for their solutions.

(Boal, 1995, pp. 14-15)

Forum theatre, itself, is intended to generate collaborative and critical dialogue among the audience members. Scenes about a social or political situation are created and presented to audiences. Actors' and audience members' roles are interchangeable - audience members can join the scene and are invited to stop the action and suggest alternative actions that will lead to more desirable results. These spect-actors (Boal, 2002) thus become active transformers of the scene.

Consistent with Boal's work, in our use of forum theatre, the scenes are not intended to culminate in a single solution or play out to a single "correct" conclusion. Instead, the involvement of audience members may generate multiple possibilities or follow different trajectories. Thus, we hope that audience members and we, as researchers, might "become more conscious of the other person's possibilities" (Taussig, Schechner, \& Boal, 1990, p. 62).

\section{Creating the Scene}

We derived our forum theatre scenes through a process of collaborative analysis. We began by working in small groups of academic, community, and self-advocate co-researchers. We read interview transcripts together, making note of what seemed important, what questions were generated for us, and what we thought was "going on" in the interviews. After we had worked through about ten interviews, we paused to take stock of our salient learning to that point. Among the most compelling revelations were the institutional and family responses to labeled people considering parenthood. Team members were particularly moved by the responses to expectant parents. Focusing on these, we spent considerable time thinking and talking about the key responses labeled people received with respect to parenting - the underlying assumptions, motivations, content, tone, and individual and collective effects of these responses on labeled people.

At that point, the academic researchers (Ignagni and Fudge Schormans) returned to the transcripts to identify various excerpts that exemplified the 
responses. These were compiled and reviewed again by the larger team. Then, working with a few interviews, we began to devise our scenes. Through brainstorming and considering our own experiences with families, co-researchers settled on dinner scenes with family and friends, and from that point began to improvise and work the situations until we had four loosely scripted scenes.

Returning to the transcripts, academic team members re-worked the scripts again to integrate exemplary and analytically significant participant quotations into the scenes, checking with the larger research team to make sure they fit with team members' initial analyses and ideas. Throughout the process we tried to make the narratives presented in individual participant interviews more complex, weaving in other responses as much as possible. Our objective was to develop scenes that would render visible and juxtapose subjugated, dominant, dis/ableist, resistant, and other perspectives. The questions raised in the scenes deal with value and ethics (professional and societal), and with power and privilege. Our hope is that through repeated workshopping of these and other scenes, we can reveal many other experiences and meanings of intellectual and developmental disability, parenting/parenthood, and intimate life. Below we present the script for one scene.

\section{Making Lemonade}

By: Christine Austin, Joanna Drassinower, Kareem Elbard, Rainbow Hunt, Ashley Judge, Renee Morin, Romeo Pierre, Tania Jivraj, Kate Peters, Sarah Wren.

Characters: Narrator; Mary; Tyrone; Christine Johnson; Joe Johnson; Gladys (the social worker); Father Murphy (the priest); Uncle Bob; Aunt Sarah

Seating Arrangement:

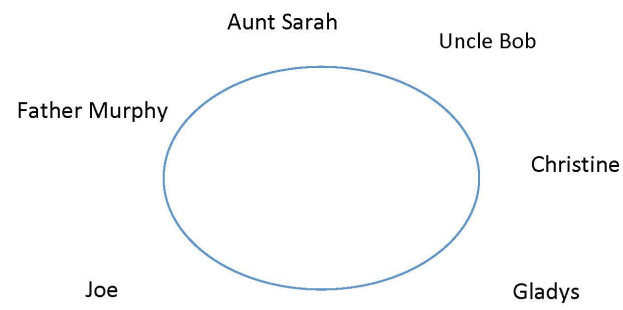

Mary Tyrone 
Narrator: Hello, I am part of the Reimagining Parenting Possibilities SelfAdvocate Parenting Working Group. I'll be your narrator for this afternoon. We're going to present a four act play. We ask that you save your questions until the end.

In our first act, we will be joining the Johnsons for dinner. Let me introduce you to the family. Here at the head of the table is Joe Johnson - the family patriarch. At the other end of the table is his wife Christine Johnson. Among the friends and family present there are a couple people we should pay attention to.

This is Father Murphy, the local priest. Here's Uncle Bob - he's never really fit into the family. Here's his partner Aunt Sarah, she has a heart of gold. And here is Gladys, the neighbor. She just happens to be a worker at Children's Aid.

And finally, here's Tyrone and Mary - both of whom have been labeled with developmental disabilities. Mary is Joe and Christine's daughter and Tyrone is her current boyfriend. They have a big announcement to make!

(Everybody fusses and makes comments about how good the roast beef was. People around the table are all talking to each other. Mary and Tyrone are sitting close together and whispering to each other-they are nervous and excited.)

Mary: (clinks her glass, excitedly) Excuse me, excuse me.

Christine: Everybody, Mary is trying to get our attention.

Mary: Thanks Mom. Everybody, Tyrone and I have something we'd like to share with you.

Christine: Which is?

Mary: (very happy) Tyrone and I are having a baby. I'm six weeks pregnant! (A collective gasp from everyone except Tyrone)

Dad: You are???!!!

Christine: Oh my god! What are we going to do now?! We have to fix this somehow!

Gladys: (calmly) Well, Christine, Joe, don't worry. There's lots we can do to help out.

Dad: Like what? 
Gladys: Well, these two (pointing to Mary and Tyrone, speaking sarcastically) can come down to the office and they can complete some paperwork. We have a lot of forms for them to fill out. Then at a later date, you and Christine can come and fill out some forms. Then one of my colleagues can come here for a home visit and you can fill out some more forms. Now if you all come to these meetings and fill out the correct forms, we can be finished by the time the baby is about 4 years old.

Christine: (talking to Mary and Tyrone, speaking angrily) Hold on a minute! You two think you're going to be parents? There's part of me that wants to say you made your bed, you sleep in it.

Mary: We're prepared to take on that responsibility. We want to raise this child just like you raised me. We're excited about being a family.

Dad: Well that's great, that's what we would want you to do... but that's not very realistic.

Christine: Oh my, this is all such a shock!

Uncle Bob: (gruffly) Oh calm down Christine. It's still early. The girl said it was only six weeks along. She could (whispering) terminate. You know get rid....

Mary: (upset) But I don't want to!

The priest: (interrupting, indignant) Excuse me; the Johnson's are an upstanding Catholic family. Their faith forbids them from taking a life! A life, even at six weeks, is a life. If the Johnson's had those kinds of values, Mary would not be with us today.

Mary: I really want to have this baby....

Tyrone: Mr. and Mrs. Johnson, since we're having this baby, I would like to ask for Mary's hand in marriage. (takes Mary's hand and speaks lovingly)

(silence)

Dad: Well young man, Mary's mother and I will have to think about that!

Christine: Yes, at this point, I can see us helping Mary raise the baby. But you Tyrone...... 
The priest: I'm not sure I can actually marry you both Tyrone. Marriage is a sacrament. I can only marry people who understand the sacred bond they're about to enter.

Gladys: And you're getting way ahead of yourself Tyrone. Of course you might be able to have supervised visits with the child, but just because you are the biological father, doesn't mean Children's Aid will think you can be an active parent to this child. In fact, before either of you can seriously think about parenting this child, you will need to have a parenting capacity assessment and a risk assessment. And I'm not at all sure about the outcome....

Aunt Sarah: (to Gladys) So are you suggesting that we bring them into Children's Aid. I've known these two for a long time - they wouldn't intentionally hurt a child!

Gladys: Not intentionally...

Tyrone: (upset) But why should I have supervised visits? It's our kid. We created a baby out of our love. And we will love this child - not hurt it.

Uncle Bob: (interrupting) But really, do you think those two can do it. (To Tyrone) Do you two have jobs?

Mary: Well we have part-time jobs. They are supported employment but we do have jobs! Tyrone and I love each other and we have so much love to give this baby!

Uncle Bob: Do you make enough money to live on?

Mary: Well, we do get ODSP. ${ }^{3}$ It's not a lot. But we want to raise our child just like mom and dad did....

Uncle Bob: Well, do you have a place to live?

Tyrone: Well, yes. We live in a nice assisted living building. It's a SIL. ${ }^{4}$

Uncle Bob: Can you raise a family there?

Tyrone: (shakes his head)

\footnotetext{
${ }^{3}$ ODSP (Ontario Disability Support Program) is an income transfer program aimed at people with disabilities in the province of Ontario, Canada.

${ }^{4}$ SIL (Supported Independent Living).
} 
Narrator: Tyrone is feeling like he has been shut out of this family and out of his baby's life.

Mary: Well, no, I don't think so... but Mom and Dad, Tyrone and I want to learn how to support this child, just like you raised me.

Uncle Bob: Do you know how to change a diaper?

Dad: Do you know how to take care of a colicky baby?

The priest: Do you know how to soothe a teething baby?

Aunt Sarah: Do you know what to do if the baby cries all night?

Mary: (pleading) I promise, we'll take parenting classes. We can....

Christine: Well, somebody has to take control of this mistake. Don't you agree Joe?

Aunt Sarah: But listen, you both will get more ODSP if you have a baby, right? I heard that you can get nursery furniture, a stroller, extra money for diapers and formula. Maybe an agency like Children's Aid can help with extra support?

Gladys: (sarcastically) Oh yeah, Mary has hit the jackpot! No seriously, the ODSP increase is minimal. And the agency is concerned with getting families to raise their children independently.

Joe: (to Christine) Oh, yeah. It took two of them to do it, but I think at this point, you and I will need to take over. They don't have the finances, they don't have a house...

Narrator: Tyrone and Mary understand that they will have no say in their baby's life. They start moving away from the table, crying and holding each other for comfort.

(Here Tyrone and Mary start moving back, away from the table and the rest of the family. They are holding each other and clearly upset.)

Aunt Sarah: Well, maybe that's the answer. Maybe, Joe and Christine, you can raise the baby. It pains me to think of that little bairn alone in the world. You always wanted a second child. 
The priest: With your faith, the way you value life. You see every child as a blessing - how wonderful that you might consider raising this child in this faithful home.

Gladys: And you're so well resourced as a family. And you are still young enough to raise your grandchild.

The priest: What a lucky child this will be!

Christine: I'm feeling a little better about this. Joe, what colour should we paint the bedroom?

Joe: I should go out to the garage and see if we have anything stored away from when Mary was young. Maybe this one will be a boy. I could teach him woodworking.

Aunt Sarah: Oh, I can start my knitting again - I love making booties.

Uncle Bob: This family amazes me in the way it can make lemonade out of any lemon of a situation!

\section{The End}

At this point, the narrator goes around the table and asks each character what they want. While responses are not tightly scripted they generally reflect the following sentiments:

Joe: I just want to play golf.

Father Murphy: I want morality to prevail - and it has.

Uncle Bob: I want people around this table to be sensible! Let's be realistic, they can't parent a child.

Aunt Sarah: I just want everyone to get along.

Gladys: I'm so close to retirement; I just want this situation to get resolved without too much work or complication.

Christine: I want to make sure my new little grandchild is safe.

Tyrone: I want to be part of my child's life.

Mary: I want to raise my baby with Tyrone and I want my family to support my decision! 
The narrator then opens conversation to the audience, asking them what they think of the outcome, what feelings and thoughts it raises for them, and how they think the dynamic might have played out differently. After some discussion, audience members are invited to become spect-actors and the scene is re-enacted with audience members moving in and out of the action.

\section{Epilogue}

To date, Making Lemonade has been presented 16 times, with plans to integrate it and other scenes into more structured educational workshops. Well-received by most audiences, we are struck by some of the ways its performance both opens up and precludes the possibilities for re-imagining parenting and intimate justice for labeled people. Below we introduce some emerging questions.

\section{How Do We Reach Different Audiences?}

Our audiences have, for the most part, been comprised of academics and students (from various disciplines including social work, disability studies, midwifery, history, law, philosophy, and gender studies), although we have had several opportunities to reach out to general communities. Initially, our audiences reflected our desires to elicit feedback on our research methodology and its potential for knowledge mobilization and exchange. Working with university-based audiences also allows us to reach future practitioners directly and indirectly through those currently in positions to challenge dis/ableist discourse within curriculum, research, and policy consultation.

We have been only moderately successful in reaching practitioner audiences, especially child welfare workers. This matters because many of our participants' stories recounted hurtful experiences with child welfare, including child apprehension. Many child welfare social workers are trained and committed to an anti-oppression analysis, but this does not always extend to disability, which tends to be viewed as a clinical matter. Thus our work, which positions disability as a social construct, may not be viewed as relevant to or consistent with child welfare values. In fact, if disability is viewed as "naturally" contributing to the risk of child neglect and maltreatment, as an understandable source of parental or caregiver stress, the conflict and oppression within the scene may not be recognized.

More significantly, we are less able to access labeled people. While labeled people have been in our audiences, their numbers have been low. This difficulty speaks to the extent to which labeled people's lives remain heavily monitored and contained. Given the very high number labeled interviewees in the larger project who told us they had never previously voiced their parental 
desires, our hope is that these scenes can serve as a vehicle to begin such conversations. We also hope that theatre workshops can become a place to share practical resources to help labeled people realize their parenting dreams. We continue to struggle with how to reach labeled people.

\section{What Sorts of Narrative Interventions Emerge?}

Many audiences remark that Making Lemonade is the first time they have witnessed labeled people in a position of providing expert and legitimated knowledge. Some go as far as to admit that the workshops are the first time they have met a labeled person. Among those who work directly to support families, the scenes provided a sobering insight into the disabling and demeaning responses received by labeled prospective parents. The ways in which dis/ableism is systemically embedded are illuminated for audiences through the characters of Father Murphy and Gladys, the social worker. By entering the scene, some audience members begin to think about how to resist and transform the system. For instance, the priest is often the first character to be replaced by a spect-actor, his dialogue transformed to celebrate the disabled couple's right to and desire for loving commitment. Audiences seem to trouble the priest's moral authority, by removing scripted moral pronouncements and replacing them with words of comfort and validation. In other instances, audience members are quick to invent new characters, such as lawyers, who would help Mary and Tyrone claim their parental and intimate rights - creating a systemic enhancement of sorts. Audiences also clearly worried about interpersonal dis/ableism, crystallized in the silencing and spatial distancing of both expectant parents. Spect-actors took on the role of kindly Aunt Sarah to offer assistance instead of recrimination. Indeed, spect-actors challenged other characters (for example, Uncle Bob) on their "bullying" and "close-mindedness."

Other audience interventions have been less transformative. We focus on three consistent responses here: default to dominant models of disability, magical thinking, and the reiteration of competence.

Audiences' possibilities for Mary and Tyrone often follow one of the major models of disability: charity or rights. Of the pair, the charitable responses to disability emerge more readily. Audience members eagerly offer to lend a hand - offering advice, time, a basement apartment, a call to the congregation to donate money and baby gear - offers of assistance that rarely emerged from Mary and Tyrone's expressed concerns or wants. We suspect these responses are well-intended efforts to care and show support for the young couple. Rarely however, do audiences account for how these offers are ad hoc and contingent on the benefactor's resources and immediate priorities. We are grappling with how audiences could be supported to explore the possibility that these offers are extended on the assumption that Mary and Tyrone will ultimately enact some form of normative parenthood. Equally 
troubling, audience members never consider the thresholds to their own "giving" - what they need or expect in exchange for their goodwill.

A challenge for us is to help audiences consider these questions and to reflect on the impact of charitable responses to disabled people. The charity model positions disabled people as dependent: passive recipients of others' beneficence. Disability is understood as an individual misfortune, which underpins and explains all the troubles experienced by the disabled person. What is called for in the charity model is a gesture of assistance directed at the individual, rather than any broader social enhancement to redress exclusions from or deterrents to parenthood (Stiker, 1999; Longmore \& Umansky, 2001).

Audiences may not be conscious of this broader framing of their interventions in the scene. In times of government social spending restraint, communities, families, and individuals are called upon to assume care for one another. We are enjoined to form strong social bonds and collective care to prevent vulnerable others from slipping through an unraveling social safety net. Thus, the impulse to informally share individual resources comes in part from a practical appraisal of Mary and Tyrone's precarious material conditions (no job, low income, inadequate housing). This impulse might be fueled by a sense of active citizenship (commitment to taking responsibility for one's family/neighbours/community through civic engagement and participation), or conversely, by a disability commons (a sphere of reciprocity and mutual support outside of and contra the market) (e.g., Runswick-Cole \& Goodley, 2015). Our task within workshops is to prompt audiences to note and guard against slippage between these two positions, keeping the structural forces shaping family making in mind.

Charitable interventions have an enduring impact on labeled people's lives. While doing little to change their social and material life conditions, charity responses tell labeled people that they are objects of sympathy and pity. Labeled people may, and often do, internalize these messages, eroding their sense of worthiness and capacity to care for others. Charitable responses can be understood and felt as dis/ableist micro-aggressions, fueling psychoemotional distress (Campbell \& Oliver, 2013; Reeve, 2006). Because many disabled people's access to helpful resources and community integration is so precarious, many feel they cannot draw attention to the violent dimensions of charity. Instead they find themselves assuming a posture of deference and gratitude that keep them locked in as needy subjects.

In sharp contrast to the charitable model of disability, audiences sometimes evoke rights models of disability. This too takes different routes - sometimes as appeals to intimate human rights as articulated in the CRPD. At other times, audiences are calling for social rights; the state supported services afforded to citizens of the Global North's (former) welfare states. Disability rights have had an undeniably helpful impact on many disabled people, leading to more meaningful integration to work, education, and community life (Shakespeare, 2014). Rights have helped to spell out a minimum standard 
of treatment and promises of freedom from harm (Ignatieff, 2008). However, rights approaches have recently been criticized for creating new social divisions (Kafer, 2013; Mingus, 2011).

Rights interventions depend on a pre-given knowledge of entitlements. Yet as our research findings indicate, many labeled people do not have access to rights information. When such information is at hand it is not always in an accessible format. As such, when spect-actors bring in rights-based interventions we must stop the scene to provide a clear explanation of these rights in order for labeled people to keep pace with what is being proposed.

Other times, it is audiences themselves who raise questions about rights approaches. Audience members whose identities and histories are not tied to privileged Western nations, question the continued turn to the state, querying how intimate rights can be pursued in the context of serious material deprivation or failed governments (Ignagni, Fudge Schormans, Liddiard, \& Runswick-Cole, 2016). Even among North American and European audiences, social rights such as education, social assistance, or healthcare, might be understood as precarious. For instance, under conditions of austerity social policy, such as in the United Kingdom, disabled people have been among the hardest hit, subject to a host of benefit clawbacks (Runswick-Cole $\&$ Goodley, 2015). And while our human rights, as represented in the CRPD, are meant to help resist the erosion of hard-won entitlements, the social infrastructure enabling these claims has been dismantled and defunded (see, for example, the removal of the Canadian federal Charter Challenges program in 2006). Still more unsettling were the responses of Aboriginal participants and audience members who did not necessarily see themselves as rights-bearing Canadian "citizens," but as being in treaty relationships with the Canadian state; they were frustrated in their attempts to join in such alternate imaginings. Deepening their sense of disengagement was their understanding of disability as a colonialist category on par with gender (see also Evans, Hole, Berg, Hutchinson, \& Sookraj, 2009). While our thoughts about these interactions and responses are evolving, we wonder about the new exclusions that might be created by these ostensibly empowering interventions.

Marta Russell, late disability activist and scholar, argued that the majority of those who have benefitted from rights victories have been middle-class and otherwise privileged. Consequently, the existing rights frameworks do not reflect the life circumstances of the majority of disabled people (Russell, 1999). How can the complicated and contradictory dimensions of the ostensibly emancipatory promise of rights be surfaced with audiences? How can we teach audience members about disability rights, even as we articulate their limitations and normative underpinnings?

A second set of questions emerges when the scene's narrative plays out along a magical vein. Boal describes magical thinking as the moment audience members move the action of the scene from reality to "the realms of magic or fantasy" (2002, p. 37). Perhaps the clearest instances of this were 
audience members' efforts to convince others around the table that Mary and Tyrone could raise their child independently. This is not in itself fantastical, but the dialogue in these interventions seems to inevitably slip into playful pronouncements; the audience introduces romantic ideas about Tyrone's impending debut as a hip-hop artist, for example. To contextualize this imaginative turn, it is crucial to know that Tyrone was portrayed by a Black self-advocate (who chose the name Tyrone for the character). Although project self-advocates have found recent news reports about a young labeled father who embarked upon a rap music career, we have all agreed that the scene would not practically play out along these desirable lines. Moreover, the intervention evokes black culture in ways that seem to narrow the possible avenues to paid work and "success" to options that can only be accomplished by a very privileged few.

Another less whimsical example of magical thinking occurs when spectactors, in taking on the Gladys role, and abandon all the concomitant responsibilities of a child welfare worker. The new Gladys offers unconditional, compassionate support, much like those audience members enacting the charity model of disability. Often, one of the research team actors must challenge this intervention, noting that no child welfare worker could work in this manner, due to state-based professional practice regulations and resource realities. We try to work together to imagine how Gladys might support the Johnson family, especially Mary and Tyrone, within the constraints of her position. We appreciate the audiences' attempts to hold onto dreams that offer more hope for justice than the inadequate solutions we have at hand. At the same time, we continue nudging audiences towards more reflexive positions that unpack the interpersonal and structural dis/ableisms shaping the dinner table interactions.

Finally, we have noted that many interventions try to inculcate and assert Mary and Tyrone's ability to competently parent their future child. Sometimes this looks like skills training - offers of classes and mentoring to help Mary and Tyrone acquire and perfect the essential tasks of parenting. Other times, the interventions are more general, focusing on their (imagined) alternate areas of competence (e.g., emotional intelligence). In every presentation of the scene, a non-labeled parent in the audience will share their own knowledge gaps with the birth of their first child. Audiences suggest that "no one knows what to do" when it comes to parenting a first child, but imply that parenting knowledge is there for the taking. The assumption is that, like non-labeled first time parents, Mary and Tyrone can become "competent subjects" and competent parents.

This turn toward the issue of competence troubles the intersection of parenthood and intellectual and developmental disability. As with other interventions, education or knowledge acquisition serve to individualize the parenting problems faced by Mary and Tyrone in the scene. The approach assumes that their problem lies in a knowledge and skills deficit. Presumably this deficit can be overcome by submitting the pair to new forms of adult 
education, despite the fact that many labeled people experience education and training as arenas of extreme disempowerment (Erevelles, 2005; Watts \& Erevelles, 2004). When the scene begins to play out along these lines, we wonder how to avoid reiterating the very ground upon which labeled people are marginalized. Then our challenge in the scenes is to prompt audiences to consider why labeled people have lacked the opportunities to develop parenting knowledges and practical skills in the first place. How can we reveal the normative demands connected with any discrete body of parenting knowledge? How can we begin to de-link human value from notions of competence? How might audiences be inspired to think about alternatives to competence?

\section{Ethical Dilemmas of Performance}

In the prologue of this paper, we cited Alison Kafer's observation that those marked "feebleminded" were located "at the convergence of race, moralized gender, class and disability" (2013, p.27). As RPP members, many of us like many of our participants - live at those intersections, and wove them into the script when we could. Thus, Mary and Tyrone reflect the embodied and biographical experiences of several co-researchers and interview participants. In other scenes, Aboriginal and queer identities are reflected in the characters and their dialogue. Very specific experiences, such as inducements to voluntary sterilization; the push for termination of pregnancy; the denial, interruption, and discrediting of intimate relationships; and the separation from children are also reflected in the dynamics that play out in the different scenes.

Given that the dinner table scene involves nine characters, we have sometimes found that we did not have enough actors to occupy the available roles. Early on, we decided to invite audience members to take on a scripted role. Volunteers are quickly apprised of the character's attitude, motivations, and wants in the scene. This has meant that a volunteer actor may embody a character that has little bearing on their personal experience, raising some ethical questions. For instance, there is always a risk of enacting a sort of "cripface" with the problems that flow from non-disabled actors taking on the role of a disabled character (Harris, 2014). Our aesthetic goals for our scenes are, in practice, modest, but we do aim for actors to attempt to convey disability in ways that do not reproduce shallow stereotypes. More significantly, when labeled people represent themselves in the scene they powerfully challenge their dis/ableist characterization as voiceless, incompetent, and incomplete persons. Inevitably, there are fewer opportunities for this when labeled people are not in the scene in some substantial way - particularly when portraying a labeled character.

In a related vein, we have struggled with cross-racial representations. Tyrone is a character who appears in several scenes, always 
as an expectant father. In each case, non-disabled characters are skeptical about his suitability for fatherhood, assuming that his intimate, parental motivations are rooted in sexist exploitation and are an expression of hegemonic masculine sexual prowess. These dynamics reflect a strong racist and ableist discourse about labeled men's illegitimate paternal subjectivities, and were encountered across service provider and participant interviews. Racialized co-researchers identified the discourse immediately from transcripts and were eager to integrate it into scripts, remarking that it "felt real," while also critically acknowledging its power to constrain parenthood for all racialized men.

Audiences' response to Tyrone's role within scenes depends upon the actor. As noted above, typically Tyrone has been played by a Black coresearcher. Audiences generally responded warmly to him, inviting him to take a more active role with his current partner and asserting his capacity to be a "good father." Working with his stated desire to be part of his child's life, they repeatedly sought to bring him into the family fold. When we performed more than one scene in which Tyrone appeared, audiences speculated that his efforts to "settle down" must have been impeded by others. Without variation, audiences bestowed a type of "respectability" upon Tyrone's intentions and actions.

In the rare instance when the regular co-researcher has not been able to perform this role, non-racialized volunteers have been substituted. These instances have always provoked the audience into a more critical stance calling out the research teams for engaging in such racist stereotypes. Specifically, we are asked why we chose a name associated with Black identity for the young father. Rather than being viewed as an effort to decentre the whiteness of families, citizenship, and fatherhood through active engagement with oppressive discourses, the scene is understood as promulgating those very discourses. Ultimately, audiences recognize that racism intersects with disability and gender in the scene, although not necessarily recognizing that it also intersects in the lives of labeled people.

These different audience responses feel unsurprising, but deserve further interrogation. We wonder if Tyrone's portrayal by a Black co-researcher somehow naturalizes the racist/ableist/gendered representation of masculinity and fatherhood. While audiences do try to redress Tyrone's exclusion from his future child's life, they privilege a monogamous, involved fatherhood. We are currently working with audiences to consider how Tyrone might be able to sustain multiple connections with children and (former) partners without deferring to typical constructions of the "good father." We wonder about how to move audiences to reflect on the power relations involved in remaining silent when Tyrone is played by a Black actor.

In a variation, we notice that Mary's mother Christine, almost always played by a co-researcher, is almost never replaced or assertively challenged despite her negative responses to the news of Mary's pregnancy. We wonder if this is an attempt at political correctness. For instance, as a mother of a 
disabled young person, the character of Christine Johnson may be viewed as engaging in greater and more arduous caring labour than do other family members and mothers of non-disabled children. Perhaps audiences can sympathize with her distress about supporting her daughter through a pregnancy. Perhaps they think that to critique her is to de-legitimate the intense caring labour she presumably performs. Complicating this is the fact that Christine Johnson has, to date, always been played by a co-researcher who also uses a wheelchair. Typically, audiences greet the replacement of "mean" characters by "spect-actors" with cheers, laughter, and applause. With rare exceptions, the mean characters are portrayed by non-disabled actors. Perhaps audiences are disinclined to put co-researchers through this experience of being replaced. In a sense this reflects a larger finding from our research. In the overall study we found that non-disabled practitioners were reluctant to articulate the terms "intellectual disability/developmental disability/impairment" for fear of causing offence (Ignagni \& Schormans, 2016). Other times, we worry audiences are responding with a sort of disableism toward this co-researcher, enacting the assumption that she may not appreciate that her words and responses were offensive. That said, Christine Johnson was one of the least empowered characters around the dinner table - caught in webs of patriarchal and institutional power along with Mary and Tyrone. Replacing her may have made little difference to the overall trajectory of the scene.

Finally, we are currently grappling with the ethics involved in asking people to repeatedly embody dis/ableist violence in the scenes. This is as true for the co-researcher who is performing a parent's distress at losing custody of her child, as it is for the co-researcher voicing ableist, sexist, and racist slurs. How do we care for one another within and after each performance? And, going further, who might be precluded from embodying these characters because of their performative and rhetorical violence? We find ourselves struggling with an ethical dilemma previously raised by Ross Gray and Christina Sinding in their performance work with women living with cancer: "how carefully people should or can be 'held' in such a project" (2002, p. 134).

In this paper we have presented the script of a forum theatre scene, highlighting the eugenic legacy that shapes the current context in which labeled people consider parenthood. While the project raised many issues (including voice, the neoliberalization of research, the cultural construction of the good parent, and child welfare policy and practice), we have focused here on some questions emerging from this scene's performance. We present questions that may help us begin to map out intimate justice for labeled persons.

Reimagining parenting possibilities for labeled people is not simply important political work; it is necessary for survival. Normative understandings of parenthood fail to contest its current neoliberal formulations (self-sufficient, self-contained, competent, efficient, productive, 
and so forth). All parents are encouraged to "join the ranks of the privileged" (Mingus, 2011), which threaten to leave behind those of us who cannot easily be folded into normative structures - structures that, when they remain intact, continue to oppress (Chandler \& Ignagni, n.d). Normative parenthood fails to break with the devaluation of difference - whatever form that difference may take - and does little to loosen the knot of disability, race, gender, class, sexuality, and colonial relations that shape and maintain the marginalization and exclusion of so many who seek to build families.

As the RPP team captured in Making Lemonade, when labeled people begin to imagine their parenting possibilities, they are perceived as disruptive and are quickly contained. Within this context the difference of disability can only be seen as undesirable, a site of "no future." This cultural failure to desire, welcome, and embrace disability enacts Kathleen Lynch's idea of "affective injustice" towards disabled people as articulated by Shakespeare, and may lead to disabled people being deprived of love in their everyday lives (Lynch, 2009, as cited in Shakespeare, 2014).

We understand intimacy as close connections with others that are produced in the spaces of our lives that we consider warm, safe, and protective (Liddiard, 2016). Intimacy is private, and can involve affectionate, loving, and sexual relations. Because intimacy always involves others, it necessarily entails negotiation and reciprocity, and always blurs with our public lives (Ignagni et al., 2016). Intimacy is mediated by our material circumstances, by government policy, our human rights context, our histories, and our social locations. Rights protecting our intimate lives, such as those outlined in Article 23 of the UN CRPD, certainly make our intimate lives a matter of citizenship and, therefore, subjects of public dialogue. But rights approaches only go so far because they are difficult to enforce, they create new social divisions, they require significant material and symbolic capital to enact, and they cannot adequately address the complexity of our relationships with our partners, our children, and the other social relations that constitute our lives.

Turning to Disability Justice activist Mia Mingus (2011), we can heed her assertion that we must, "mov[e] away from an equality-based model of sameness and 'we are just like you' to a model of disability that embraces difference, confronts privilege and challenges what is considered 'normal' on every front" (n.p.). Intimate justice may attend to the sorts of questions emerging from the forum theatre scenes that we have delineated above. It demands that we attend to who has (and who does not have) access to an intimate life; whose lives are free(er) from surveillance, intrusion, and containment; and who are able to access the material and social resources that support an intimate life. We must open up space for people to build intimate lives, such as lives within families, in different ways. And we must attend to the privilege, marginalization, and violence that patterns these intimate differences such that they might be transformed to allow labeled people to partake in family making and the re-making of our worlds.

Disability, then, helps us move towards intimate justice, by troubling our 
notions of parenthood. Disability always heralds the arrival of difference and, in turn, that difference is always disruptive (Chandler \& Ignagni, n.d.). The arrival of disability in parenthood might help us imagine new ways to collectively raise children, to further de-link biology from kinship, to re-think the gendered division of caring labour, or to foster new forms of redistributive competence in family making across communities. These sorts of reimagined parenthood possibilities centre on the embodied and "enminded" experience of disability, ${ }^{5}$ move towards interdependence, and disrupt taken-for-granted notions of "Canadian parenthood." The disruption the difference of disability makes can help us interrogate what is meant by parenthood, family, and care, and can gesture to myriad new ways we might make family differently: more expansively and in ways that desire disability and the difference it makes.

\section{Acknowledgements}

This project was supported through a research grant from the Ontario Ministry of Community and Social Services, Developmental Services Branch and Ryerson University, and through Faculty of Community Services Project Funds. We wish to acknowledge the tremendous time and energy the RPP coresearchers devoted to the research, script writing, and performances. Special thanks go to Christine Austin, Joanna Drassinower, Kareem Elbard, Rainbow Hunt, Renee Morin, and Romeo Pierre. Thanks as well to our community partners, Melanie Moore, Lynda Roy, and Ashley Judge from SPIN, as well as Springtide Resources and the Centre for Independent Living Toronto. Our research assistants, Kim Collins, Tania Jivraj, and Sarah Wren were integral throughout many stages of the research and forum theatre performances, as was the project's assistant Kate Peters. Finally, we would like to thank the many labeled people and those who support them for sharing their stories with us.

\section{References}

Anderson, J., \& Phillips, J. (Eds.). (2012). Disability and universal human rights: Legal, ethical and conceptual implications of the Convention on the Rights of Persons with Disabilities (SIM special 35). Utrecht: Netherlands Institute of Human Rights, Universiteit Utrecht.

Boal, A. (2002). Games for actors and non-actors. London: Routledge.

Boal, A. (2006). Aesthetics of the oppressed. New York: Routledge.

Boal, A. (1995). Rainbow of desire. (A. Jackson, Trans). New York: Routledge.

Campbell, F. K. (2001). Inciting legal fictions-disability's date with ontology and the ableist body of the law. Griffith Law Review, 10(1), 42.

\footnotetext{
${ }^{5}$ Enminded is a term coming into use in critical disability studies. Here we use it to gesture to the countless epistemological and ontological debates about the status of the mind, consciousness, and mental representations.
} 
Campbell, J., \& Oliver, M. (2013). Disability politics: Understanding our past, changing our future. New York: Routledge.

Chandler, E., \& Ignagni, E. (n.d.). Strange beauty: Aesthetic possibilities of sustaining disability into the future. Unpublished manuscript under review.

Dowbiggin, I. (1995). "Keeping this young country sane": CK Clarke, immigration restriction, and Canadian psychiatry, 1890-1925. Canadian Historical Review, 76(4), 598-627.

Duster, T. (2003). Backdoor to eugenics. New York: Psychology Press.

Erevelles, N. (2005). Understanding curriculum as normalizing text: Disability studies meet curriculum theory. Journal of Curriculum Studies, 37(4), 421-439.

Eugenics to Newgenics. (n.d.). Key Terms. Retrieved from https://eugenicsnewgenics.com/keyterms/\#Newgenics

Evans, M., Hole, R., Berg, L. D., Hutchinson, P., \& Sookraj, D. (2009). Common insights, differing methodologies: Toward a fusion of indigenous methodologies, participatory action research, and white studies in an urban aboriginal research agenda. Qualitative Inquiry, 15(5), 893-910.

Goodley, D. (2014). Dis/ability studies: Theorising disablism and ableism. New York: Routledge.

Gray, R., \& Sinding, C. (2002). Standing ovation, Performing social science research about cancer. Walnut Creek, CA: Altamira Press.

Harris, S. J. (2014, January 14). Why the theory of everything's depiction of disability is disappointing. [Web blog post]. Retrieved from www.slate.com/blogs/browbeat $/ 2015 / 01 / 20 /$ the theory_of_everything_and_disability_why _eddie_redmayne_shouldn_t_get.html?wpsrc $=\overline{\text { fol_fb }}$

Ignagni, E., \& Schormans, A. F. (2016). Reimagining parenting possibilities: The experiences of people labeled with intellectual and developmental disabilities. International Journal of Birth and Parenting Education, 3(3), 1-4.

Ignagni, E., Fudge Schormans, A., Liddiard, K., \& Runswick-Cole, K. (2016). "Some people are not allowed to love": Intimate citizenship in the lives of people labelled with intellectual disabilities. Disability \& Society, 31(1), 131-135.

Ignatieff, M. (2008). The rights revolution. Toronto: House of Anansi Press.

Kafer, A. (2013). Feminist, queer, crip. Indianapolis, IN: Indiana University Press.

Kevles, D. J. (1985). In the name of eugenics: Genetics and the uses of human heredity. Boston, MA: Harvard University Press.

Kilkey, M., \& Clarke, H. (2010). Disabled men and fathering: Opportunities and constraints. Community, Work \& Family, 13(2), 127-146.

Liddiard, K. (2016, February). What's love got to do with it. Paper presented at the Disability and the Human Symposium, Manchester Metropolitan University, Manchester.

Longmore, P. K., \& Umansky, L. (2001). The new disability history: American perspectives. Albany, NY: New York University Press.

Malacrida, C. (2015). A special hell: Institutional life in Alberta's eugenic years. Toronto: University of Toronto Press.

McLaren, A. (2015). Our own master race: Eugenics in Canada, 1885-1945. Toronto: University of Toronto Press.

Mingus, M. (2011, August 8). Leaving evidence. [Web blog post]. Retrieved from http://leavingevidence.wordpress.com/

National Council on Disability (2012, September 27). Rocking the cradle: Ensuring the rights of parents with disabilities. Washington, DC. Retrieved from www.ncd.gov/publications/2012/Sep272012

Plummer, K. (2003). Intimate citizenship: Private decisions and public dialogues. Seattle, WA: University of Washington Press.

Reeve, D. (2006). Towards a psychology of disability: The emotional effects of living in a disabling society. In D. Goodley \& R. Lawthom (Eds.), Disability and Psychology: Critical Introductions and Reflections (pp. 94-107). Basingstoke, UK: Palgrave MacMillan

Runswick-Cole, K., \& Goodley, D. (2015). Disability, austerity and cruel optimism in Big Society: Resistance and "the disability commons." Canadian Journal of Disability Studies, 4(2), 162-186. 
Russell, M. (1999). Beyond ramps: Disability at the end of the social contract. New York: Common Courage Press.

Saxton, M. (2013). Disability and selective abortion. In L. Davis (Ed.), The disability studies reader ( $4^{\text {th }}$ ed.) (pp. 87-99). New York: Routledge.

Shakespeare, T. (2014). Disability rights and wrongs revisited ( $2^{\text {nd }}$ ed.). New York: Routledge.

Stiker, H. J. (1999). A history of disability. Ann Arbor, MI: University of Michigan Press.

Taussig, M., Schechner, R., \& Boal, A. (1990). Boal in Brazil, France, the USA: An interview with Augusto Boal. TDR (1988-), 34(3), 50-65.

Thomas, C. (2007). Sociologies of disability and illness: Contested ideas in disability studies and medical sociology. New York: Palgrave Macmillan.

Turner, B. S. (2006). Vulnerability and human rights. University Park, PA: Pennsylvania State University Press.

UN (United Nations). (2006). Convention on the rights of persons with disabilities. UN Web Services Section, Department of Public Information. Retrieved from www.un.org/disabilities/convention/conventionfull.shtml

Watts, I. E., \& Erevelles, N. (2004). These deadly times: Reconceptualizing school violence by using critical race theory and disability studies. American Educational Research Journal, 41(2), 271-299. 